\title{
Badanie własności złączy ze stali S355J2G3 spawanej laserem
}

\section{Testing of properties of laser made joints of S335J2G3 steel}

\section{Streszczenie}

Przedmiotem badań były złącza doczołowe ze stali S355J2G3 o grubości $8 \mathrm{~mm}$, spawane laserem dyskowym Nd:YAG o mocy $2 \mathrm{~kW}$ bez podgrzewania wstępnego. Wykonano analizę metalograficzną złączy, określono rozkłady twardości w obszarze spoiny, przeprowadzono statyczna próbę rozciągania złączy poprzecznych i zbadano ich udarność. Uzyskane spoiny były wolne od niezgodności spawalniczych wewnętrznych i zewnętrznych jednak twardość w spoinie wynosząca ok. 500 HV1 wskazuje na celowość zastosowania procesu podgrzewania wstępnego.

Słowa kluczowe: stal S355J2G3, badania wytrzymałościowe, spawanie laserowe

\section{Abstract}

Subject of the research were butt joints made of S335J2G3 steel of $8 \mathrm{~mm}$ thick welded by $2 \mathrm{~kW} \mathrm{Nd:YAG}$ disc laser without of pre-heating. The metallographic analysis was made, the hardness of the joint measured, static tensile test of transverse joints was conducted and impact strength measured. Welds appeared to be free of internal and external welding imperfections, the gained hardness in the joint - some $500 \mathrm{HV} 1$ makes the consideration of preheating reasonable however.

Keywords: steel S355J2G3, strength tests, laser welding

\section{Wstęp}

Stale konstrukcyjne o podwyższonej wytrzymałości mają obszerne zastosowanie w przemyśle. Używa się ich m.in. do budowy mostów, części maszyn czy wytwarzania prętów, blach i rur. Łączenie takich elementów odbywa się najczęściej za pomocą spawania, dlatego od stali konstrukcyjnych wymaga się dobrej spawalności. Coraz więcej procesów spawalniczych ulega automatyzacji, co w konsekwencji przyczynia się do zminimalizowania pracy ludzkiej. Dzięki temu obniżają się koszty, rośnie poziom bezpieczeństwa pracy, wydajność oraz jakość wykonanych spoin.

Stal S355J2G3 spawa się przeważnie metodą MAG. Postęp technologiczny sprawia, że spawanie laserowe zyskuje coraz większą popularność. Jest to proces łączenia, który różni się pod wieloma względami od metod konwencjonalnych. W zależności od użycia metody spawania, napotkać można szereg zalet jak i problemów. Dlatego interesujące wydaje się przebadanie własności spoin wykonanych laserem.

Do badań wykonano typowe złącze próbne doczołowe o wymiarach $350 \times 300 \mathrm{~mm}$.

\section{Statyczna próba rozciągania złączy i udarność}

Badania wytrzymałości na rozciąganie wykonano według PN-EN ISO 4136 na próbkach poprzecznych pobranych ze złącza próbnego. Rozciąganie przeprowadzono na ma- szynie wytrzymałościowej MTS 810 na zakresie pomiarowym $0 \div 250 \mathrm{kN}$. Przykładowy wykres z próby rozciągania oraz wygląd zerwanej próbki pokazano na rysunkach 1 i 2. Porównanie własności stali i złączy spawanych laserem zestawiono w tablicy I. Jak można zauważyć na rysunku 2 przełom próbki nastąpił w materiale rodzimym stali. Wytrzymałość złącza wyniosła $571 \mathrm{MPa}$.

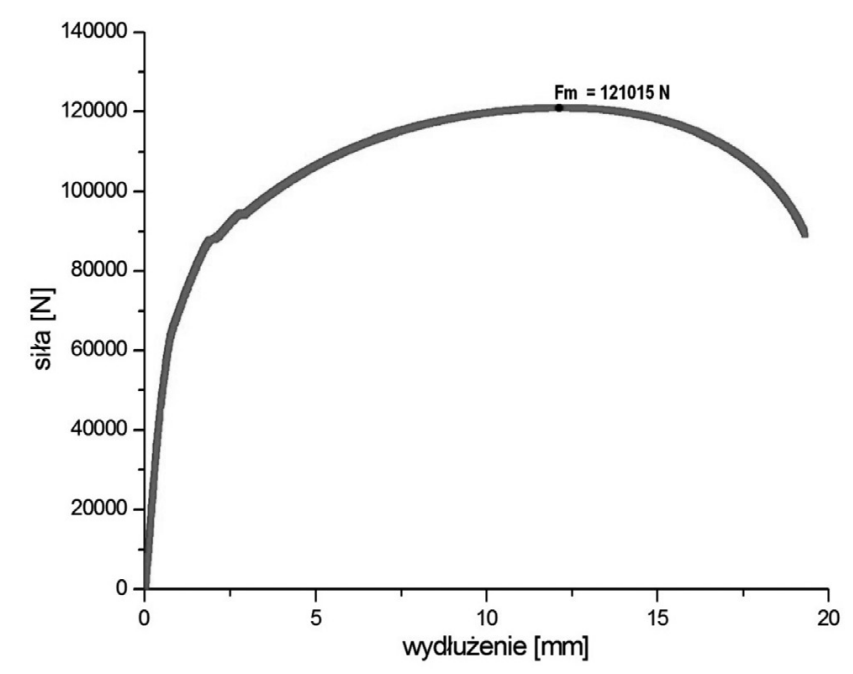

Rys. 1. Wykres rozciągania doczołowego złącza poprzecznego ze stali S355J2G3 spawanego laserem

Fig. 1. Curve of elongation of the laser made butt joint of the S335J2G3 steel

Dr inż. Piotr Białucki, dr inż. Artur Lange, dr inż. Wiesław Derlukiewicz, prof. dr hab. inż. Andrzej Ambroziak, mgr inż. Jakub Kędzia, inż. Mateusz Kusztal - Politechnika Wrocławska.

Autor korespondencyjny/Corresponding author: artur.lange@pwr.edu.pl 
Tablica I. Własności wytrzymałościowe stali S355J2G3 oraz złączy spawanych laserem

Table I. Properties S355J2G3 strength steel and laser welded joint

\begin{tabular}{|l|c|c|c|}
\hline \multicolumn{1}{|c|}{ Próbka } & $\mathrm{R}_{0,2 \mathrm{~min}}[\mathrm{MPa}]$ & $\mathrm{R}_{\mathrm{m},}[\mathrm{MPa}]$ & Norma \\
\hline Stal & 355 & $470 \div 630$ & PN-EN ISO \\
\hline Złącze spawane & - & 571 & - \\
\hline
\end{tabular}

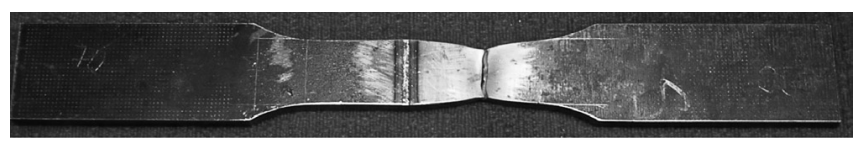

Rys. 2. Złącze ze stali S355J2G3 po próbie rozciągania Fig. 2. Joint of the S335J2G3 steel after tensile test

Próbę udarności wykonano na młocie Charpy'ego o energii początkowej mota $100 \mathrm{~J}$. Ze względu na grubość stali wynoszącą $8 \mathrm{~mm}$ zastosowano próbki o grubości 7,5mm. Badane próbki nie uległy pęknięciu. Uzyskane wyniki należy więc traktować jako orientacyjne. Zbadana udarność wyniosła więcej niż 164 KCV100/7,5. Wygląd próbki po próbie udarności przedstawiono na rysunku 3.

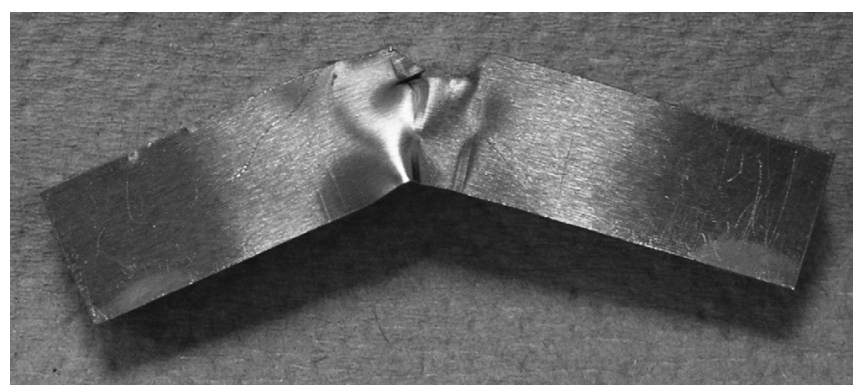

Rys. 3. Próbka złącza ze stali S5333J2G3 spawanej laserem po próbie udarności

Fig. 3. Laser made joint of the S335J2G3 steel after impact test

\section{Pomiary twardości}

Pomiary twardości wykonano na mikro twardościomierzu Sinowon HVS-1000 przy obciążeniach 9,8 N i 0,98 N. Układ linii pomiarowych na przekroju spoiny pokazano na rysunku 4, a wyniki pomiarów twardości przedstawiono na rysunku 5.

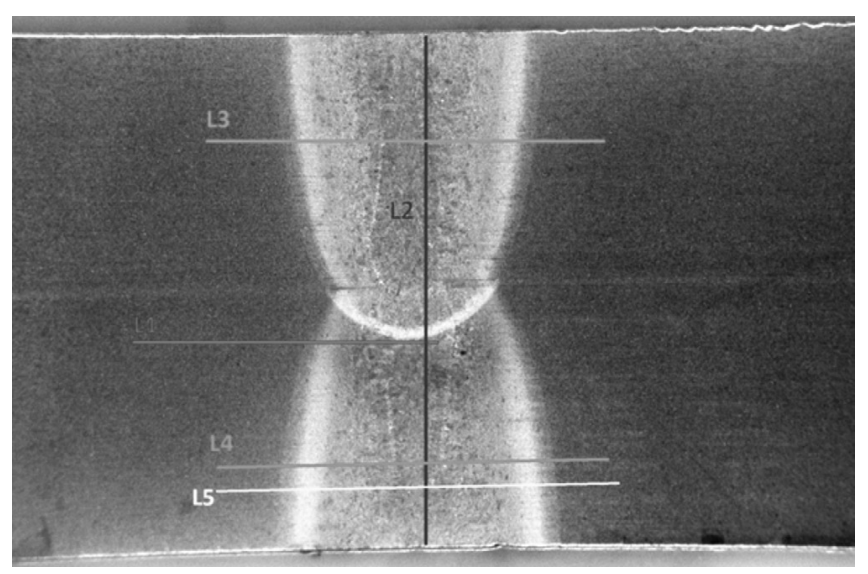

Rys. 4. Układ linii pomiaru twardości na przekroju poprzecznym zgładu spoiny, linie L1 $\div$ L4 przy obciążeniu 9,8 N, linia L5 przy obciążeniu $0,98 \mathrm{~N}$

Fig. 4. Lines of hardness measurement on the cross section of the joint. Lines L1-L4 under 9,8 N load, L5 under 0,98 N
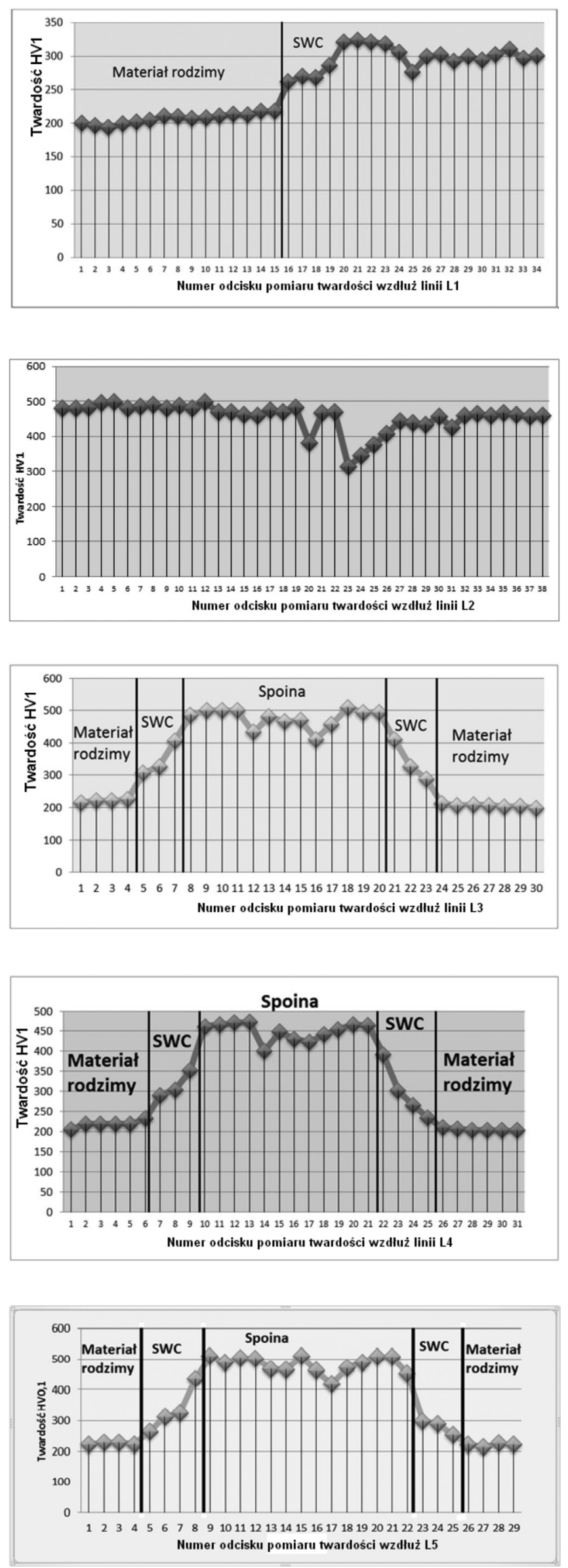

Rys. 5. Rozkłady twardości na przekroju złącza ze stali S355J2G3 spawanego laserem wzdłuż linii pomiarowych L1 do L5 pokazanych na rysunku 4

Fig. 5. Hardness on the cross section of the S335J2G3 steel made joint along L1-L5 lines shown in the figure 4 


\section{Badania metalograficzne}

Badania metalograficzne wykonano na mikroskopie metalograficznym OLYMPUS K40M. Struktury obserwowano w świetle widzialnym przy powiększeniach 50x i 500x na zgładach trawionych odczynnikiem Nital 3\%. Mikrofotografie struktur występujących w badanych złączach spawanych pokazano na rysunkach $6 \div 10$.

$\mathrm{Na}$ rysunku 6 przedstawiono strukturę krystalizacji spo-

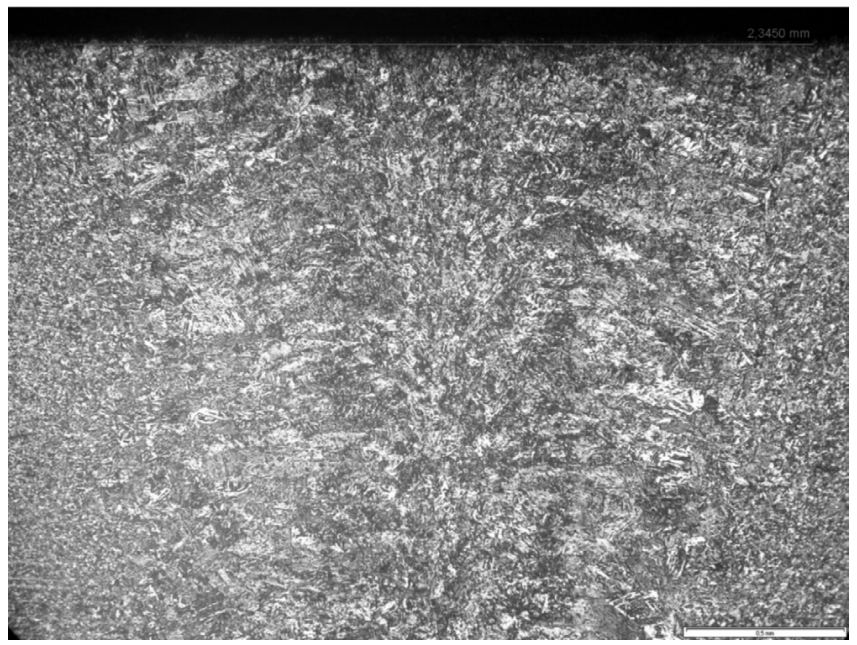

Rys. 6. Makrostruktura spoiny na stali S355J2G3 wykonanej laserem Fig. 6. Macrostructure of the laser made joint of S335J2G3 steel

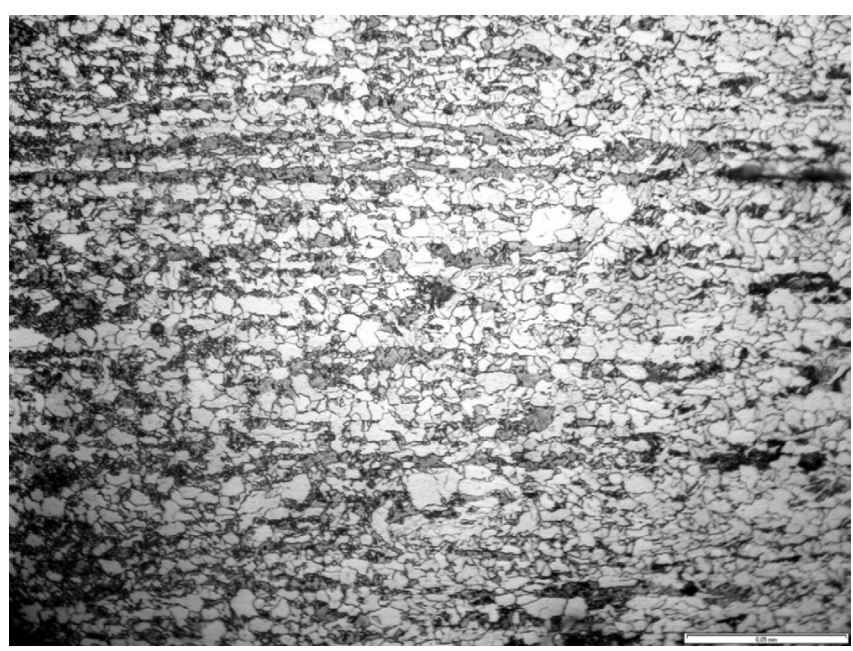

Rys. 7. Mikrostruktura materiału rodzimego stali S355J2G3 w pobliżu strefy SWC spoiny wykonanej laserem

Fig. 7. Microstructure of the base metal of the S335J2G3 steel close to the HAZ

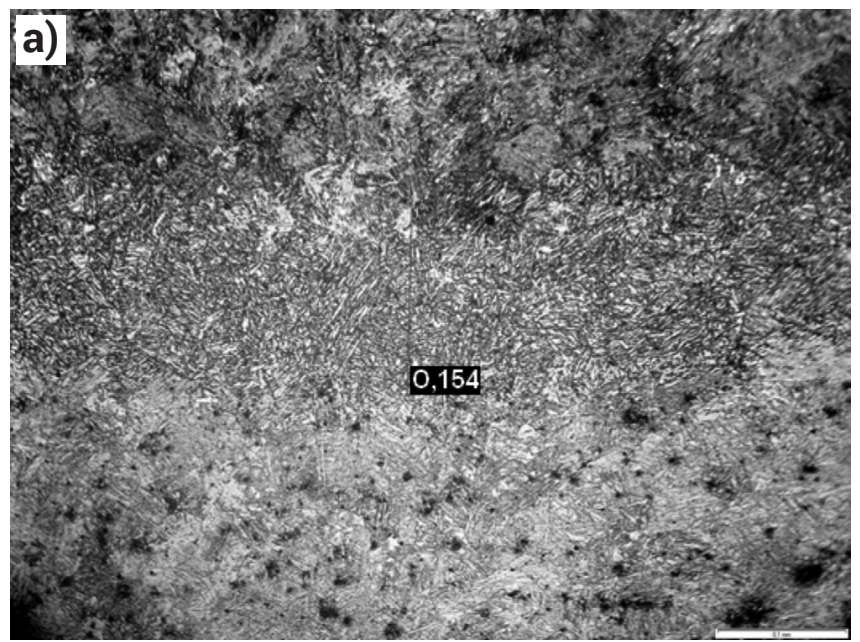

iny o budowie osiowo dendrytycznej, której twardość wynosi ok. 500HV1. Materiał rodzimy wykazuje strukturę ferrytyczno-perlityczną w układzie pasmowym (rys. 7) o twardości ok. $200 \mathrm{HV} 1$. W strefie SWC o szerokości ok. 0,5 mm występują wąskie obszary struktury gruboziarnistej (przy linii wtopienia, rys. 8) i struktury drobnoziarniste charakterystyczne dla normalizacji w dalszych obszarach (rys. 9). W obszarze przetopienia spoiny o szerokości ok. 0,154 mm od drugiego ściegu występuje struktura ferrytu w układzie płytkowym o twardości ok. 300HV1.

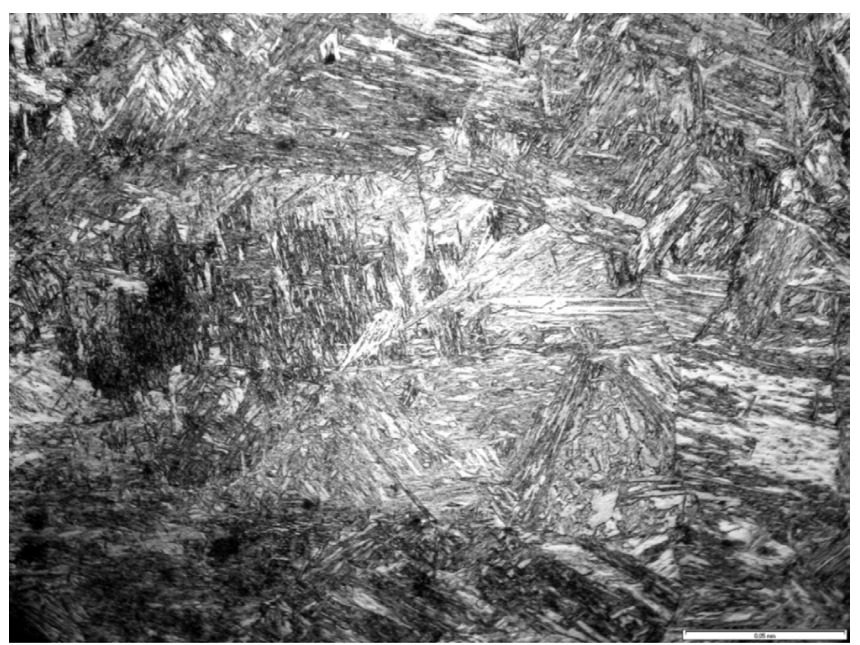

Rys. 8. Mikrostruktura gruboziarnistej strefy przegrzania SWC spoiny wykonanej laserem na stali S355J2G3

Fig. 8. Microstructure of coarse-grain overheated zone of HAZ of the joint

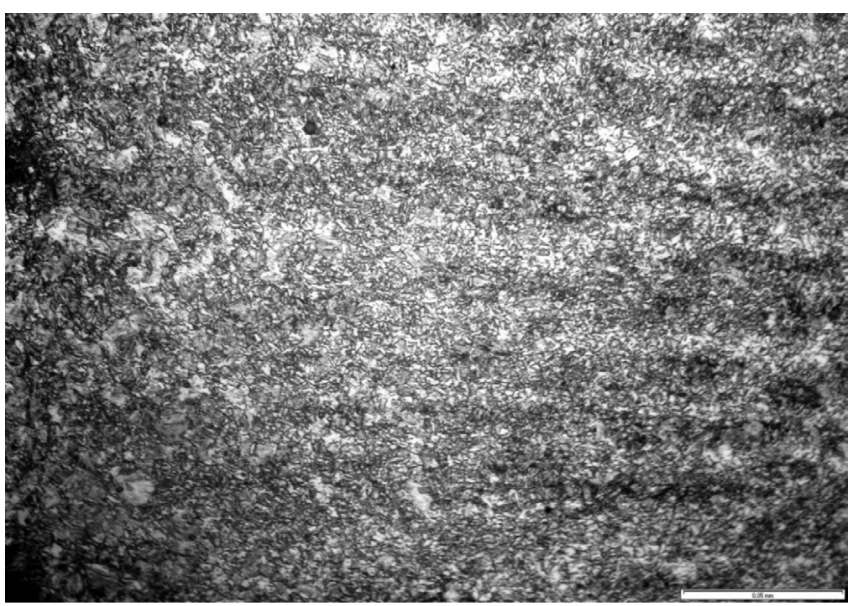

Rys. 9. Mikrostruktura drobnoziarnistej normalizacji pełnej i częściowej strefy SWC spoiny wykonanej laserem na stali S355J2G3

Fig. 9. Microstructure of fine-grain full and partial normalization zone of HAZ of the joint

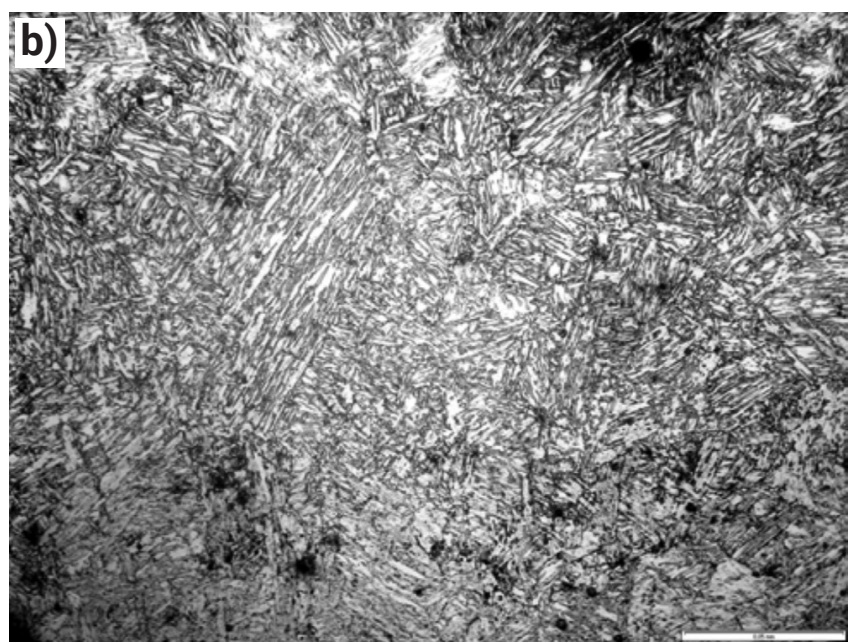

Rys. 10. Makro- i mikrostruktura obszaru spoiny wykonanej laserem na stali S355J2G3 od przetopienia drugim ściegiem: a) pow. 50x, b) pow. 500x Fig. 10. Macro- and microstructure of the laser made joint area of the S355J2G3 steel after re-melting by the second bead: a) magn. 50x, b) magn. 500x 


\section{Wnioski}

1. Spawanie laserem dyskowym Nd:YAG o mocy $2 \mathrm{~kW}$ blachy o grubości $8 \mathrm{~mm}$ wymagało wykonania dwóch ściegów z dwóch stron blachy dla uzyskania spoiny z pełnym przetopieniem. Wielkość zakładki ponownego przetopienia wyniosła $0,15 \mathrm{~mm}$. Wykonanie spoiny bez materiału dodatkowego wymagało starannego dopasowania oraz precyzyjnego dopasowania do siebie blach bez odstępu.

2. Wytrzymałość złączy doczołowych na rozciąganie wyniosła $571 \mathrm{MPa}$. Przełom próbek występował w materiale rodzimym poza obszarem spoiny. Sposób odkształcenia próbek po rozciąganiu wyraźnie wskazuje na znaczną różnicę twardości między spoiną i materiałem spawanym.

3. Udarność złącza spawanego wynosi więcej niż 164 KCV100/7,5. Z uwagi na małą energię młota udarnościowego nie nastąpiło rozdzielenie próbki.

4. Pomiary twardości przekroju poprzecznym złącza wykazały, że najwyższą twardość ma spoina (470 - 510 HV1), która różni się od materiału rodzimego (210 - 220 HV1). Z uwagi wysoką twardość w spoinie, wskazującą na niebezpieczeństwo powstawania pęknie na zimno w przypadku sztywnego węzła, wskazane jest zastosowanie podgrzania wstępnego.

5. Badania metalograficzne wykazały charakterystyczne struktury dla złączy spawanych z badanej stali, lecz z mniejszą szerokością strefy SWC, która wyniosła ok. 0,5 mm. W spoinie występuje martenzyt niskowęglowy, przy linii wtopienia obecna jest gruboziarnista struktura przegrzania stali z martenzytem i bainitem, a za nią w strefie SWC występuje drobnoziarnista struktura odpowiadająca strukturze po normalizacji.

6. Pomiary twardości i badania wytrzymałości na rozciąganie wykazały, że struktura martenzytyczna w spoinie może świadczyć o niskiej plastyczności złącza spawanego aczkolwiek badania udarności wykluczyły powstanie kruchego martenzytu.

\section{Literatura}

[1] PN-EN ISO 9015-1 - Badania niszczące złączy spawanych metali - Badanie twardości - Część 1: Badanie twardości złączy spawanych łukowo.

[2] PN-EN ISO 9015-2 - Badania niszczące złączy spawanych metali - Badanie twardości - Część 2: Badanie mikrotwardości złączy spawanych łukowo.

[3] PN-EN ISO 4136 - Badania niszczące spawanych złączy metali - Próba rozciągania próbek poprzecznych.

[4] PN-EN ISO 9016 - Badania niszczące złączy spawanych metali - Badanie udarności - Usytuowanie próbek, kierunek karbu i badanie.

[5] Kusztal M.: Badania własności złączy ze stali konstrukcyjnej spawanych laserem. Praca dyplomowa, PWr 2014r. 